\title{
Differences in Grading Systems Among Canadian Universities
}

\author{
HUGH TAYLOR*
}

\begin{abstract}
This study examines the great diversity of grading systems used in twenty-three of Canada's largest universities. For analysis purposes the grading systems are divided into two main types. The first consists mainly of Ontario institutions using a percentage scale with the number of passing grades ranging from three to twelve. The second includes universities from nearly all sections of Canada where the four to ten passing grades are equated with either descriptive terms or grade-point categories. From the analysis various suggestions are offered which, if adopted, should greatly improve the communication value of grades and increase their effectiveness in decision-making.
\end{abstract}

\begin{abstract}
RÉSUMÉ
Différences entre les systèmes de classement utilisés par nos universités canadiennes

Cette étude examine la grande diversité des systèmes de classement des 23 universités numériquement les plus importantes du Canada. Dans le but de simplifier l'analyse, les systèmes de classement sont divisés en deux catégories principales. Dans la première, il s'agit essentiellement des institutions ontariennes utilisant une échelle de pourcentages où les étudiants reçus sont côtés de 3 à 12. Dans la deuxième, il est question des universités de presque partout ailleurs au Canada où les résultats des candidats reçus sont côtés de 4 à 10 et égalés soit à des termes descriptifs soit à une évaluation numérique. Diverses suggestions sont tirées de l'analyse. Si adoptées, ces suggestions devraient améliorer sensiblement la possibilité de comparer les cotes employées et permettre de s'en servir efficacement pour arriver à des décisions à l'égard des étudiants.
\end{abstract}

What does a "B" mean?
1. $65 \%$
4. Very Good
2. $79 \%$
5. Superior
3. Good
6. All of the above

*Associate Professor, Faculty of Education, University of Victoria. 
If you chose "All of the above" as the answer to the question, "What does a B mean?", then you are either test-wise, a good guesser, or knowledgeable about the great differences in grading systems and letter grade meanings used by Canadian universities. What does a B mean? It means 65\% at Queen's but not at Toronto, the largest university in Canada, where the B range extends from 70\% to 79\%. It means Good at Windsor, Very Good at New Brunswick, and Superior at Manitoba. And to prove the West really is different, it should be noted that the University of British Columbia, Canada's second largest university, does not even issue a $\mathrm{B}$ or any other letter grade.

This article describes the grading systems of twenty-three English-speaking Canadian universities, each of which enrolls a minimum of five thousand undergraduate students. The survey includes universities in all provinces except Prince Edward Island. The article concludes with suggestions on how the grading system in Canadian universities may be improved.

For purposes of analysis, the various grading systems in Canadian universities have been categorized into two main groupings. Table 1 outlines the percentage equivalents associated with letter grades used by ten universities, eight of which are situated in Ontario. The number of different grades issued by the universities range from 3 to 12 with a median of 4 . A minimum percentage of 80 associated with an A grade is consistent over all ten universities. However, the minima for lower grades show great variability with B's ranging from 64 to 73, C's from 55 to 63 , and D's from 45 to 52 .

Table 2 presents an outline of grading systems used in ten universities that equate grades with numerical equivalents and/or descriptive phrases. These universities are located in eight provinces. The number of different grades issued by universities listed in Table 2 range from 4 to 10 with a median of 8 . Compared with those listed in Table 1 , the Table 2 universities which issue the largest number of different grades tend to be the most recently established. As with the Table 1 universities, there appears to be a consistency among them in defining an A grade to mean excellent performance. However, as with Table 1 universities, there is a definite lack of consistency in the use of descriptive terms associated with grades less than $\mathrm{A}$. Depending upon where a student is registered, his transcript containing a B could be interpreted as Good, Very Good, or Superior; while his C grade could mean Acceptable, Pass, Fair, Satisfactory or Average.

Three of Western Canada's large universities have each developed a unique grade reporting system that does not fit into either of the two previous schemes. British Columbia uses a three category system: Class 1(80-100), Class 2 (65-79), and Pass (50-64). Alberta has a nine point system of which six are unconditional passing grades: 9 and 8 (excellent), 7 and 6 (good), 5 and 4 (pass), with 3 (conditional), and 2 and 1 (fail). Saskatchewan uses four categories as follows: DIVISION I (80-100)-3 merit points, DIVISION II (70-79)2 points, DIVISION III (60-69)-1 point, and DIVISION IV (50-59).

A study of Tables 1 and 2 reveals the great diversity of letter grade systems used in Canadian universities. Only two groupings of universities use similar meanings for their passing grades. The Toronto, McMaster and Western Ontario group have a comparable four category system, while Waterloo and Carleton each have twelve similar categories.

One would imagine that at the university level a symbol would have a very specific meaning. In the sciences and mathematics, symbols are used which have internationally common meanings. Basic terms in the arts and humanities usually have agreed upon mean- 
Table 1

Percentage Equivalent of Unconditional Passing Letter Grades Used at Selected Canadian Universities

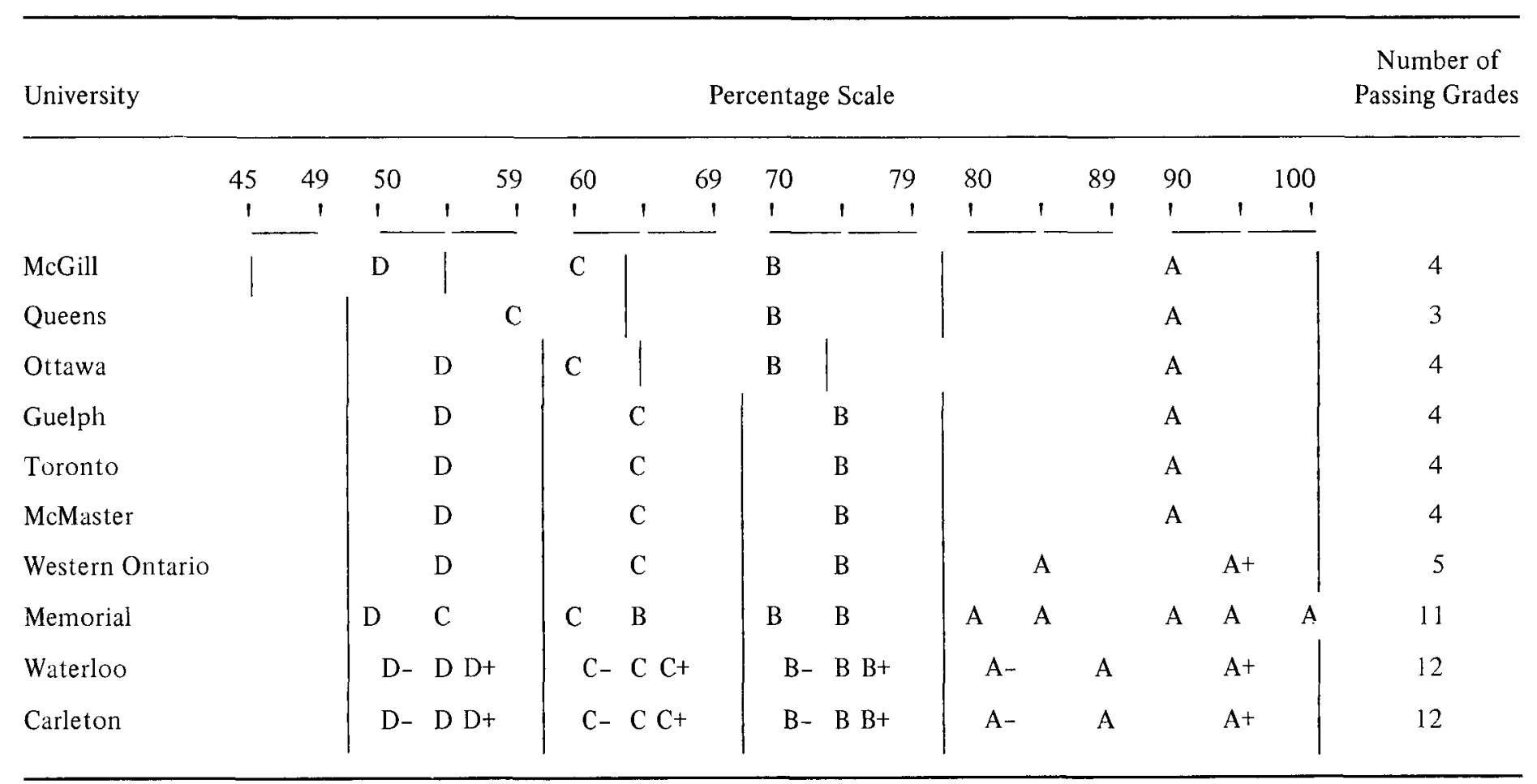


Table 2

Qualitative and Numerical Equivalents of Unconditional Passing Grades

Used at Selected Canadian Universities

\begin{tabular}{|c|c|c|c|c|c|c|c|c|c|c|}
\hline \multirow[b]{2}{*}{$\begin{array}{l}\text { Passing } \\
\text { Grades }\end{array}$} & \multicolumn{10}{|c|}{ University } \\
\hline & $\begin{array}{l}\text { Simon } \\
\text { Fraser }\end{array}$ & $\begin{array}{c}\text { New } \\
\text { Brunswick }\end{array}$ & Victoria & Windsor & Dalhousie & York & Manitoba & Calgary & $\begin{array}{l}\text { Sir George } \\
\text { Williams }\end{array}$ & Ryerson \\
\hline $\mathrm{A}^{+}$ & 1st (4) & $(4.3)$ & 1st (9) & Excellent & 3 & 9.2 & Exceptional & $\begin{array}{l}\text { Outstanding } \\
\text { (4) }\end{array}$ & & \\
\hline A & 1st (4) & $\begin{array}{l}\text { Excellent } \\
(4.0)\end{array}$ & 1 st $(8)$ & Excellent & 3 & 8 & Excellent & $\begin{array}{c}\text { Excellent } \\
\text { (4) }\end{array}$ & Excellent & Excellent \\
\hline A- & 1st (4) & $(3.7)$ & 1st (7) & Excellent & 3 & & & & & \\
\hline B+ & 2nd (3) & $(3.3)$ & $2 \mathrm{nd}(6)$ & Good & 2 & 7 & $\begin{array}{l}\text { Very } \\
\text { Superior }\end{array}$ & $\begin{array}{l}\text { Very Good } \\
\text { (3) }\end{array}$ & & \\
\hline
\end{tabular}


51 Differences in Grading Systems Among Canadian Universities

$\infty$

$\stackrel{\mathscr{s}}{\mathscr{2}}$

\begin{tabular}{l}
7 \\
0 \\
0 \\
0 \\
2 \\
\hline
\end{tabular}

$\frac{0}{\frac{0}{0}}$

莡

$\underset{\substack{0 \\ \square \\ 0 \\ 0}}{0}$
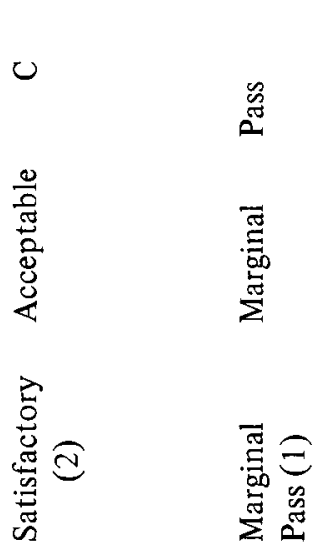

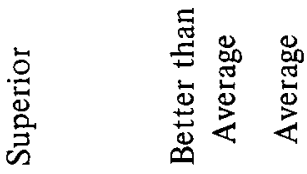

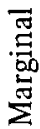

$r$

6

$\infty$

6

n $\quad$ t

$m \sim$

$\checkmark$

$\infty$

N N -20

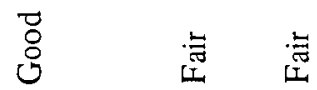

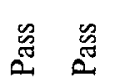

a

() $\overparen{\Xi} \overparen{d}$

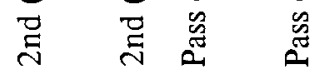

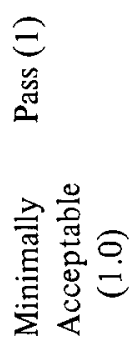

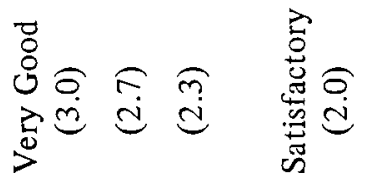

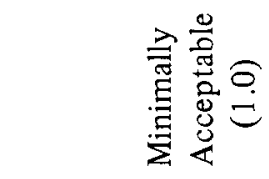

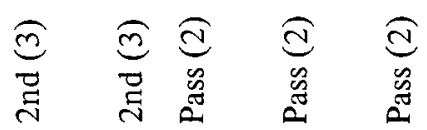

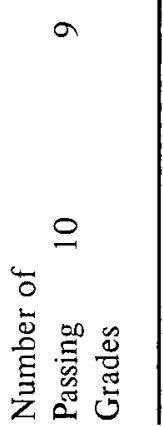

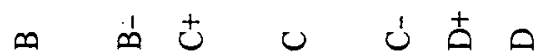


ings. However, in the administrative offices of universities dealing with admission and certification of students, the meaning of the basic grading symbol system can only be described as chaotic. Surely individuals and committees would save thousands of decision-making hours if, as a first step, a simple, agreed upon grading system were adopted by the major universities across Canada. The following assumptions and suggestions are offered as a basis for deliberations on the perennial topic of how the university grading system can be improved.

First, let us start with an assumption about the responsibility of a faculty member regarding course organization and the use of letter grades. Students enter a course with varying academic backgrounds, intellectual levels, interests, study habits, and motivations. Given this great variability in student talent, it is the responsibility of each faculty member to design his course to allow each student to achieve at his highest level, working within the constrictions of the limited resources and time available. Students vary greatly in their academic talents and rates of learning at the beginning of a course, and if it (the course) is designed to challenge each student to work at his maximum intellectual level, the variability of talent should be increased at the conclusion of the course. Teaching toward the average is as ineffectual as teaching toward competency at the minimum essentials level. Teaching toward the average limits the opportunities for high ability students. Teaching toward the minimum essentials level denies the great majority of students a chance to use their talents effectively. Organizing a course so as to challenge each student toward maximum achievement requires a measurement and evaluation system that can validly and reliably place students in a variety of grade categories. For example, the passfail model used to certify a person's ability for car driving has very limited application in a university. At the conclusion of a course, a professor should have accumulated enough data for making decisions as to which students are average (the majority will be average by definition), above average, and excellent, as well as those who are lacking the minimum standards. Note the categories involved describe a positively skewed distribution -- one well suited as a guide for assigning letter grade frequencies at tertiary institutions. Accepting the foregoing arguments as reasonable, the next task faced by university personnel is to determine the number of letter grades required for effective reporting purposes.

The majority of Table 1 universities have less than five passing grade categories, whereas the majority of Table 2 universities have more than five. A question frequently asked within faculty committees charged with reviewing the grading system is how many grades would an ideal system use. Without entering into the rather complicated psychometric rationale involved, the answer can be stated generally and simply: the more grade levels provided, the more accurate the grade report will be. To provide for large classes and courses that cover an academic year, most measurement specialists would recommend that a minimum of ten grades (including fail) should be used. Applying this criterion to Table 1 and Table 2 universities results in only seven out of twenty universities achieving this minimum standard required for accurate grading.

Accepting the viewpoint of specialists in educational measurement that a large number of grade categories is preferable to a small number, one is faced with the problem of deciding whether, for example, the system used at Memorial (eleven category-percentage) is superior to that used at Windsor (nine category-descriptive). The specialists have for many years opted for the category-descriptive system. 
They argue that letter grades based on a percentage scale, as used by Table 1 universities, have outlived their usefulness and should be abandoned The following difficulties associated with the percentage grade scales lead inevitably to this conclusion. The percentage system is a typical example of the tail wagging the dog. A neophyte teacher, seeing that the official rule of the university requires that letter grades be equated with percentages, attempts to design his examinations so that the results will fit into his preconceived ideal distribution of letter grades. The most experienced and talented test constructors find this task to be impossible. What inevitably happens is that the raw score distribution is transformed by a simple linear technique in order that the students' scores can be reported in terms of the school's official percentage scheme. All scores have either a constant added or subtracted in order to have the percentages fit the ideal ranges. This application of a fixed translation process makes no sense whatever and is also a waste of professional time.

Another factor, closely related to the difficulty of attempting to design a test that will result in the appropriate number of student scores fitting into predetermined percentage categories, is that of obtaining data which has maximum reliability. Other things being equal, the reliability of test scores is a function of the range of scores. The larger the range, the more confidence one has in measuring individual differences among students. With objective type tests, appropriate for efficient measurement of a large body of content and higher intellectual problem solving abilities, the most reliable data is secured when the average (mean) score is slightly above the fifty percent level. Designing reliable tests of this type and then applying the percentage standards of Table 1 universities would result in nearly one-half the students failing each examination! Of course, in practice the opposite is common - tests are designed that tend to be too easy to be optimally discriminating. This practice encourages the use of inefficient tests, such as those composed of items measuring little beyond the memory of specific facts and which therefore can be answered by almost all the low ability students in a class. A more reasonable procedure would be to attempt to design objective tests so that the average score is approximately fifty percent of the items, and to recognize that professional judgment must be applied in assigning various cut-off points to define letter grade equivalents.

A third factor that complicates the use of a percentage equivalent for grades scale is the lack of meaning as to what a percentage score refers. What does a $0 \%$ mean in freshman calculus? Does it mean the student knows absolutely nothing at all about the calculus? It is doubtful. What does $100 \%$ mean in freshman psychology? Does it mean that the student knows all there is to know and understand about the subject? It is doubtful. Does $50 \%$ in freshman English mean 50\% in freshman mathematics mean $50 \%$ in freshman physics mean $50 \%$ in freshman philosophy? It is doubtful. A $50 \%$ on an easy exam may mean very low achievement, whereas a $50 \%$ on a very difficult exam in another subject may mean high achievement. Percentage correct has no meaning in courses at the university level where the subject areas vary greatly in difficulty although it may have some meaning in a highly structured subject like arithmetic at the early elementary school level. If $0 \%, 50 \%$, and $100 \%$ have no agreed upon or inherent meaning, obviously neither do any other selected points such as $80 \%$ or $70 \%$ which are frequently cited as minimum $\mathrm{A}$ and $\mathrm{B}$ grades.

Abolishing percentage grade scales in the largest and oldest universities in Canada is, of course, easier said than done. Grading systems are part of the institutional tradition and culture. One can imagine the difficulties involved in attempting to convince members of a 
department or faculty to change their pattern of grading behavior when it is so deeply ingrained and habitual. It is likewise difficult to imagine all the problems involved in attempting change across ten universities. However, the challenge to abolish the percentage grade scale must be advocated vigorously.

\section{Summary}

A great variety of grading systems are used in Canadian universities. Two suggestions have been offered for improving the effectiveness of the grading systems. First, universities should use a minimum of nine passing grades. Second, percentage equivalents of grades should be phased out and replaced with a grade category-descriptive system. 